\title{
Rheumatoid arthritis in a rural South African Negro population
}

\author{
P. BEIGHTON,* L. SOLOMON, AND H. A. VALKENBURG $\dagger$ \\ From the Epidemiological Research Unit, Department of Orthopaedic Surgery, \\ University of the Witwatersrand, Johannesburg, South Africa
}

\begin{abstract}
Beighton, P., Solomon, L., and Valkenburg, H. A. (1975). Annals of the Rheumatic Diseases, 34, 136. Rheumatoid arthritis in a rural South African Negro population. (1) An epidemiological study of a rural African community has been carried out in the Western Transvaal. Altogether 801 respondents over 15 years old were examined; radiographs of the hands and feet were obtained in all these individuals. Serological tests for rheumatoid factor were carried out on 516 blood samples. (2) The diagnosis of inflammatory polyarthritis was based on a modification of the Rome Criteria of 1961. Two categories were defined: 'definite' and 'probable' rheumatoid arthritis. (3) In this population inflammatory polyarthritis was much less common and much milder in its manifestations than in European and American peoples. The prevalence of 'definite' rheumatoid arthritis was $0.12 \%$, and of 'definite' and 'probable' rheumatoid arthritis combined, $0 \cdot 87 \%$. Such changes as were encountered on clinical and radiological examination were invariably mild; no respondent in the entire survey had clinical features that would have been accepted in the ordinary way as those of rheumatoid arthritis. (4) The latex fixation test (LFT) was positive in $8.9 \%$ of the sera tested; the modified LFT after inactivation of the serum at $56^{\circ} \mathrm{C}$ was positive in $15.1 \%$ of cases. Similar findings in West African populations have been explained on the basis of alteration of the immune response by widespread parasitic infections. No obvious aetiological factor of this type was found in the present survey.
\end{abstract}

Rheumatoid arthritis, once thought to be extremely rare in tropical and subtropical climates, has now been described in several African populations (Hall, 1966; Gelfand, 1969; Kanyerezi, 1969; Greenwood, 1969; Kanyerezi, Baddeley, and Kisumba, 1970; Anderson, 1971). However, its precise incidence and distribution in these peoples is still unknown, although casual observation suggests that there may be significant differences in the frequency of the disease and its mode of expression between Africans and Caucasians, and possibly even between different populations within the African group.

Until recently only one major prevalence study had been been carried out in tropical Africa-that of Muller (1970) who conducted surveys in three villages in Liberia and Western Nigeria. He found that inflammatory polyarthritis was much less common in these areas than in other parts of the world, but noted cautiously that the findings were not necessarily representative of the populations of those countries as a whole. Clearly, a number of similar studies in different cultural and environmental zones are required to substantiate the claim that rheumatoid arthritis is rare in the African Negro.

The present paper reports the results of an epidemiological survey of rheumatoid arthritis in a rural South African Negro population.

\section{Demography}

The survey was carried out in the village of Phokeng, which is situated 100 kilometres north-west of Johannesburg in open bush veld. The summers here are hot and the winters warm, average daily temperatures varying from $36.5^{\circ} \mathrm{C}$ in January to $20.6^{\circ} \mathrm{C}$ in July. Average rainfall is $620 \mathrm{~mm} /$ year and the humidity is low.

The people of Phokeng are the Tswana, a Bantu-speak- : ing race believed to have descended from the Negroes of Central Africa. They number just over 10000, half of whom are under the age of 18 years. As in most African villages of this country, there is a preponderance of women in the middle and older age groups, due to the temporary absence of the men working in nearby towns and cities. 
Almost all the present inhabitants of Phokeng have been born in the village or in the surrounding district.

The economy of Phokeng is based to a large extent on remittances sent home by those working in other parts of the country. However, cattle husbandry and small-scale farming are still practised and food crops, particularly maize, are grown on tribal lands. This particular village is unusual in that it draws a substantial revenue from mining operations conducted by outside companies on land that belongs to the Tswana.

All these factors combine to make this a fairly prosperous people. The villagers are reasonably well housed and well nourished; malnutrition is uncommon though infants and children still suffer the effects of incorrect feeding, rather than underfeeding. The general health of the population is good, and tuberculosis, which was a major problem in the past, is now well controlled.

The tsetse-fly area of Botswana does not extend to Phokeng and for this reason trypanosomiasis is rare. Mosquitoes are a nuisance during the wet season but they do not carry malaria; indeed, the condition is virtually unknown throughout the Western Transvaal. Schistosomiasis is common in surrounding villages but it is not endemic in Phokeng.

Good medical services are provided at a general hospital in the nearby town of Rustenburg. The water supply comes from bore-holes scattered throughout the village. Water is pumped out manually and carried in buckets to the homes. Private bore-holes have been sunk by the more affluent villagers. The fluoride content of the drinking water varies considerably from one bore-hole to another, but in none was it more than 8 p.p.m., which is considered acceptable by the public health authorities.

Educational facilities in Phokeng are excellent by African standards. Over $95 \%$ of the children attend primary school and about $20 \%$ complete their secondary education, the young people sometimes remaining at school past the age of 20 . There are 3 primary schools and 2 secondary schools, all staffed by locally recruited teachers, many of whom are graduates of training colleges in the larger centres. Two crèches cater for preschool children.

\section{Methods}

Six blocks of 60 homes were randomly chosen and a complete census was carried out in each area. The purpose of this study was carefully explained to each individual by assistants recruited in the village. At the appointed time those willing to participate were collected in groups and transported to the small hospital serving one of the nearby platinum mines.

A full clinical examination was carried out on each respondent and blood was taken from all the adults. Ultimately 1183 individuals were examined; 801 were over 15 years of age, representing a completion rate of $85 \%$ of this segment of the population. The survey was undertaken within a period of 8 weeks.

An attempt was made to obtain radiographs of the hands and feet in every case and of the pelvis and spine in those over 45 years old. Altogether 853 radiographs of the hands and 804 radiographs of the feet were obtained; they were examined on two separate occasions by one investigator (L.S.) and checked by two outside observers.
Serum specimens were examined for the presence of rheumatoid factor (RF) by the latex fixation test (LFT) and the human erythrocyte agglutination test (HEAT). In addition, the LFT was measured after inactivation of inhibitor by incubating the serum at $56^{\circ} \mathrm{C}$. Titres of 1 in 640 or more for the LFT, and 1:32 or more for the HEAT, were regarded as positive, as these were the values obtained in less than $5 \%$ of a standard European population.

A modification of the combined Rome criteria (Kellgren, Jeffrey, and Ball, 1963a) was used in assessing the presence of inactive rheumatoid arthritis. The criteria may be summarized as follows.

(i) Past history of polyarthritis.

(ii) Symmetrical deformity of peripheral joints, and especially of the metacarpophalangeal or metatarsophalangeal joints, with involvement of at least one hand or foot.

(iii) $X$-ray changes of rheumatoid arthritis of grade 2 or more (de Graaff, Laine, and Lawrence, 1963; Kellgren, Jeffrey, and Ball, 1963b).

(iv) Positive serological test for rheumatoid factor.

A diagnosis of 'definite' is given if three or four of these criteria are fulfilled. Furthermore, the diagnosis may be negated by any of the exclusions listed in the American Rheumatism Association's criteria of 1958 (Ropes, Bennett, Cobb, Jacox, and Jessar, 1959).

In attempting strict application of the above criteria it was realized that a past history of polyarthritis was too unreliable to be included, and it was therefore decided that only those fulfilling the remaining criteria should be called 'definite' rheumatoid arthritis, and those fulfilling two of the criteria should be called 'probable' rheumatoid arthritis. This was motivated also by the fact that the clinical and radiographic features were invariably of mild degree.

\section{Results}

There was no case of active rheumatoid arthritis in the entire population investigated.

\section{CLINICAL FINDINGS}

Seven respondents, four women and three men, presented clinical features suggestive of mild inflammatory polyarthritis. Their ages ranged from 58 to 98 years; none was noticeably disabled and none had sought treatment for the relatively mild complaints. Of these individuals, three had the radiographic changes of grade 2 erosive arthritis of the metacarpophalangeal or metatarsophalangeal joints. None showed the classical changes of advanced rheumatoid arthritis. Two, a 98-year-old woman and a 63-yearold man, had positive serological tests for rheumatoid factor.

\section{RADIOLOGICAL FINDINGS}

Thirteen examples of grade 2 arthritis of the metacarpophalangeal or metatarsophalangeal joints were found in the radiographs of the hands and feet; this represents $1.6 \%$ of those over 15 years old and $3.5 \%$ 
of those over 35. Five of them presented as well demarcated, pocketed erosions of somewhat doubtful significance; nevertheless, they were counted so as not to exclude any possible case of rheumatoid arthritis. Of these 13 cases, three had clinical features suggestive of polyarthritis, four had positive rheumatoid factor tests, and one had both clinical and serological findings compatible with rheumatoid arthritis.

\section{SEROLOGICAL FINDINGS}

The results of the serological investigations for rheumatoid factor are shown in Tables I and II. The LFT was determined in 516 individuals, 192 men and 324 women: 46 ( 17 men and 29 women) had titres above $1: 640$, representing $8.9 \%$ of the total tested. In both sexes the percentage of positive results increased with age, rising from $2.8 \%$ in the 15 - to 24 -year cohort to $16 \%$ in the 65 - to 74 -year cohort.

After incubation of the serum at $56^{\circ} \mathrm{C}$ the LFT was positive in 26 men and 32 women. This represented $15.1 \%$ of those over 15 years in whom the test was carried out. As before, the proportion of positive tests increased with age, rising from $7 \%$ in the 15 - to 24 -year age group to $25.3 \%$ in the 65 - to 70 -year age group.

The HEAT was carried out in 514 individuals (192 men and 322 women); six men and six women had positive tests, representing $2.3 \%$ of the total. Again the percentage of positive results increased with age, from $0.7 \%$ in the youngest cohort to $5.6 \%$ in the oldest.
In nine males and nine females both tests were positive. Four of these, three men and one woman, had radiographic signs of erosive arthritis.

EVALUATION BY COMBINED CRITERIA

On the basis of the modified Rome criteria only one respondent, a 98-year-old woman, had 'definite' rheumatoid arthritis and six ( 5 men and 1 woman) had 'probable' rheumatoid arthritis. For the population over the age of 15 years ( 801 individuals) this represents a prevalence of $0.12 \%$ for 'definite' rheumatoid arthritis and $0.87 \%$ for 'definite' and 'probable' rheumatoid arthritis combined. Considering the sexes separately in this population group, $1.6 \%$ of the males and $0.4 \%$ of the females were affected (Table III).

In those over 35 years ( 371 individuals) the prevalence was $0.27 \%$ for 'definite' rheumatoid arthritis and $1.88 \%$ for 'definite' and 'probable' rheumatoid arthritis combined.

OTHER RHEUMATIC DISORDERS

One respondent, a 66-year-old man, had clinical and radiographic signs of ankylosing spondylitis. The serological tests for rheumatoid factor in this case were negative.

\section{Discussion}

Comparison of disease prevalence in different peoples is strictly valid only if population structure and

Table I Titre distribution of latex fixation test in 516 respondents aged 15 years and over

\begin{tabular}{|c|c|c|c|c|c|c|c|c|c|c|c|c|c|}
\hline \multirow{2}{*}{$\begin{array}{l}\text { Age } \\
\text { (years) }\end{array}$} & \multirow{2}{*}{$\begin{array}{l}\text { Sera } \\
\text { tested }\end{array}$} & \multicolumn{11}{|c|}{ Reciprocal titre } & \multirow{2}{*}{$\begin{array}{l}\geqslant 640 \\
(\text { no. })\end{array}$} \\
\hline & & $\leqslant 20$ & 20 & 40 & 80 & 160 & 320 & 640 & 1280 & 2560 & 5120 & 10240 & \\
\hline \\
\hline $\begin{array}{l}15-24 \\
25-34\end{array}$ & $\begin{array}{l}70 \\
28\end{array}$ & $\begin{array}{l}65 \\
24\end{array}$ & 二 & 1 & 二 & $\overline{-}$ & $\overline{1}$ & $2 *$ & $\overline{3 *}$ & 二 & $1^{*}$ & 1 & 4 \\
\hline $35-44$ & 31 & $\begin{array}{l}24 \\
27\end{array}$ & - & E & - & - & 1 & - & $2^{*}$ & $\overline{1^{*}}$ & 二 & 二 & $\begin{array}{l}3 \\
3\end{array}$ \\
\hline $45-54$ & 40 & 34 & - & - & - & 1 & 1 & $1^{*}$ & - & - & 1 & $\overline{2 *}$ & 4 \\
\hline $55-64$ & 64 & 58 & - & - & - & - & - & $2^{*}$ & $3^{*}$ & $1^{*}$ & - & - & 6 \\
\hline $65-74$ & 53 & 47 & - & - & - & - & - & $2^{*}$ & $1^{*}$ & - & - & $2+1^{*}$ & 6 \\
\hline $75 \leqslant$ & 38 & 35 & - & - & - & - & - & - & $1^{*}$ & - & - & & 3 \\
\hline Total & 324 & 290 & - & 1 & - & 1 & 3 & 7 & 10 & 2 & 2 & 8 & 29 \\
\hline Total \% & $100 \cdot 0$ & $89 \cdot 5$ & - & $0 \cdot 3$ & - & $0 \cdot 3$ & 0.9 & $2 \cdot 2$ & $3 \cdot 1$ & $0 \cdot 6$ & $0 \cdot 6$ & $2 \cdot 5$ & \\
\hline \multicolumn{14}{|l|}{ Males } \\
\hline $15-24$ & 72 & 71 & - & 1 & - & - & - & - & - & - & - & - & 0 \\
\hline $25-34$ & 18 & 16 & - & - & - & - & 1 & - & - & - & $1^{*}$ & - & 1 \\
\hline $35-44$ & 17 & 16 & - & - & - & - & - & - & $1^{*}$ & - & - & - & 1 \\
\hline $45-54$ & 21 & 20 & - & - & - & - & - & $\overline{0}$ & - & - & - & 1 & 1 \\
\hline $55-64$ & 26 & 19 & - & 1 & 1 & - & - & $2^{*}$ & - & - & - & $2+1 *$ & 5 \\
\hline $65-74$ & 22 & 15 & - & - & - & - & 1 & - & $1^{*}$ & $1+1^{*}$ & $1^{*}$ & & 6 \\
\hline $75 \leqslant$ & 16 & 12 & - & - & - & - & 1 & - & $1^{*}$ & $1^{*}$ & - & 1 & 3 \\
\hline Total & 192 & 169 & - & 2 & 1 & - & 3 & 2 & 3 & 3 & 2 & 7 & 17 \\
\hline Total \% & $100 \cdot 0$ & $88 \cdot 0$ & - & 1.0 & 0.5 & - & $1 \cdot 6$ & 1.0 & $1 \cdot 6$ & $1 \cdot 6$ & 1.0 & $3 \cdot 6$ & \\
\hline
\end{tabular}

* Prozone serum. 
Table II Titre distribution of HEAT in 514 respondents aged 15 years and over

\begin{tabular}{|c|c|c|c|c|c|c|c|c|c|c|c|c|c|}
\hline \multirow{2}{*}{$\begin{array}{l}\text { Age } \\
\text { (years) }\end{array}$} & \multirow{2}{*}{$\begin{array}{l}\text { Sera } \\
\text { tested }\end{array}$} & \multicolumn{11}{|c|}{ Reciprocal titres } & \multirow{2}{*}{$\begin{array}{l}\geqslant 32 \\
(\text { no. })\end{array}$} \\
\hline & & $\leqslant 4$ & 4 & 8 & 16 & 32 & 64 & 128 & 256 & 512 & 1024 & 2048 & \\
\hline \multicolumn{14}{|l|}{ Females } \\
\hline $15-24$ & 67 & 20 & 38 & 8 & 1 & - & - & - & - & - & - & - & 0 \\
\hline $25-34$ & 30 & 11 & 13 & 4 & 2 & - & - & - & - & - & - & - & 0 \\
\hline $35-44$ & 30 & 13 & 11 & 3 & 3 & - & - & - & - & - & - & - & 0 \\
\hline $45-54$ & 40 & 19 & 17 & 4 & - & - & - & - & - & - & - & - & 0 \\
\hline $55-64$ & 64 & 19 & 29 & 13 & 1 & - & - & - & - & 1 & - & - & 2 \\
\hline $65-74$ & 53 & 18 & 19 & 12 & 3 & - & - & 1 & - & - & - & - & 1 \\
\hline 75 & 38 & 16 & 15 & 4 & - & 1 & 1 & - & - & - & 1 & - & 3 \\
\hline Total & 322 & 116 & 142 & 48 & 10 & 2 & 1 & 1 & - & 1 & 1 & - & 6 \\
\hline Total \% & $100 \cdot 0$ & 36.0 & $44 \cdot 1$ & 14.9 & $3 \cdot 2$ & 0.6 & $0 \cdot 3$ & $0 \cdot 3$ & 0.0 & $0 \cdot 3$ & $0 \cdot 3$ & & \\
\hline \multicolumn{14}{|c|}{ Males } \\
\hline $15-24$ & 73 & 38 & 29 & 5 & - & 1 & - & - & - & - & - & - & 1 \\
\hline $25-34$ & 18 & 7 & 5 & 4 & 1 & - & 1 & - & - & - & - & - & 1 \\
\hline $35-44$ & 17 & 5 & 5 & 6 & 1 & - & - & - & - & - & - & - & 0 \\
\hline $45-54$ & 20 & 9 & 7 & 3 & - & 1 & - & - & - & - & - & - & 1 \\
\hline $55-64$ & 26 & 10 & 8 & 4 & 1 & 1 & 1 & - & - & 1 & - & - & 3 \\
\hline $65-74$ & 22 & 7 & 10 & 4 & 1 & - & - & - & - & - & - & - & 0 \\
\hline 75 & 16 & 8 & 5 & 2 & 1 & - & - & - & - & - & - & - & 0 \\
\hline Total & 192 & 84 & 69 & 28 & 5 & 3 & 2 & - & - & 1 & - & - & 6 \\
\hline Total \% & $100 \cdot 0$ & $43 \cdot 8$ & 35.9 & $14 \cdot 6$ & $2 \cdot 6$ & 1.6 & 1.0 & 0.0 & 0.0 & 0.5 & 0.0 & 0.0 & \\
\hline
\end{tabular}

Table III Age and sex specific prevalence of combined 'definite' and 'probable' rheumatoid arthritis (801 respondents 15 years old and over)

\begin{tabular}{|c|c|c|c|c|c|c|c|c|c|c|c|c|}
\hline \multirow{2}{*}{$\begin{array}{l}\text { Age group } \\
\text { (years) }\end{array}$} & \multicolumn{4}{|c|}{ Males } & \multicolumn{4}{|c|}{ Females } & \multicolumn{4}{|c|}{ Total respondents } \\
\hline & No. & $\%$ & $\begin{array}{l}\text { Affected } \\
\text { by } R A\end{array}$ & $\%$ & No. & $\%$ & $\begin{array}{l}\text { Affected } \\
\text { by } R A\end{array}$ & $\begin{array}{l}\% \\
\text { affected }\end{array}$ & No. & $\%$ & $\begin{array}{l}\text { Affected } \\
\text { by } R A\end{array}$ & $\%$ \\
\hline $15-24$ & 182 & $58 \cdot 5$ & 0 & 0 & 198 & $40 \cdot 4$ & 0 & 0 & 380 & $47 \cdot 4$ & 0 & 0 \\
\hline $25-34$ & 17 & $5 \cdot 5$ & 0 & 0 & 33 & $6 \cdot 7$ & 0 & 0 & 50 & $6 \cdot 2$ & 0 & 0 \\
\hline $35-44$ & 18 & $5 \cdot 8$ & 0 & 0 & 33 & $6 \cdot 7$ & 0 & 0 & 51 & $6 \cdot 4$ & 0 & 0 \\
\hline $45-54$ & 20 & $6 \cdot 4$ & 1 & 5 & 46 & $9 \cdot 4$ & 0 & 0 & 66 & $8 \cdot 2$ & 1 & $1 \cdot 5$ \\
\hline $55-64$ & 31 & $10 \cdot 0$ & 2 & $6 \cdot 5$ & 74 & $15 \cdot 1$ & 0 & 0 & 105 & $13 \cdot 1$ & 2 & 1.9 \\
\hline $65-74$ & 24 & $7 \cdot 7$ & 1 & $4 \cdot 2$ & 61 & $12 \cdot 4$ & 0 & 0 & 85 & $10 \cdot 6$ & 1 & $1 \cdot 2$ \\
\hline $75 \&$ over & 19 & $6 \cdot 1$ & 1 & $5 \cdot 3$ & 45 & $9 \cdot 2$ & 2 & $4 \cdot 4$ & 64 & $8 \cdot 0$ & 3 & $4 \cdot 7$ \\
\hline $\begin{array}{l}\text { Total } \\
15 \text { years } \\
\& \text { over }\end{array}$ & 311 & 100 & 5 & $1 \cdot 6$ & 490 & 100 & 2 & 0.4 & 801 & 100 & 7 & 0.87 \\
\hline
\end{tabular}

methodology are satisfactorily standardized. In practice this is seldom possible and the present investigation is no exception; indeed, nowhere are the difficulties of the epidemiological method more apparent than in this study of a rural African community at a stage somewhere between emergence from a tribal culture and assimilation into an industrial society. Migration of young people, and especially men, tends to distort the structure of the village population towards the older age groups, with females outnumbering males by two to one.
Problems of communication and precise interpretation lessened the value of purely subjective information, and the comparatively detailed A.R.A. criteria for the diagnosis of rheumatoid arthritis, upon which many of the important European and American studies are based, could not be applied in the present field survey. Instead, the Rome criteria were adopted, with the emphasis on objective evaluation of simple clinical, radiological, and serological factors. It must be emphasized that the combination of a population weighted towards the older age groups and excluding 
many of the fittest young men in the village, together with the simplified diagnostic criteria, would produce a bias towards overestimation of the prevalence of chronic inflammatory polyarthritis in this population.

Lawrence (1969) has remarked on the fact that previous surveys have shown little difference in the prevalence of 'definite' rheumatoid arthritis in different populations in the northern hemisphere. Estimates vary from $0.7 \%$ in Pittsburgh, Pa., U.S.A. (Cobb, Warren, Merchant, and Thompson, 1957), to $3.0 \%$ in Heinola, Finland (Laine, 1962). On the other hand, the milder forms of inflammatory polyarthritis differ widely in their prevalence in different countries, estimates of 'definite' and 'probable' rheumatoid arthritis combined ranging from $2.7 \%$ in the Pittsburgh survey to $11.0 \%$ in Jamaica (Lawrence, Bremner, Ball, and Burch, 1966).

In the present survey there was only one instance of 'definite' rheumatoid arthritis, a prevalence of $0.12 \%$ in the population over 15 years. Although rheumatoid factor tests were carried out in 189 out of 426 respondents between 15 and 35 years of age, this is still a valid estimate as none of the remaining 237 individuals had either clinical polyarthritis or radiological signs of erosive arthritis. On the same basis the prevalence of 'definite' and 'probable' rheumatoid arthritis combined in those over 15 years was $0.87 \%$. These estimations are significantly lower than those reported in European and American populations and support the impression that rheumatoid arthritis is rare in certain African populations.

\section{AGE AND SEX}

Most previous studies have shown an increasing frequency of rheumatoid arthritis with age, the maximum prevalence usually being in the sixth or seventh decades; except in the Amerindians (Bunim, Burch, and O'Brien, 1964) women are more often affected than men.

The present survey revealed a similar age-related change in prevalence, and the one case of 'definite' rheumatoid arthritis occurred in an elderly female. Combined 'definite' and 'probable' rheumatoid arthritis, however, was four times as common in men as in women (Table III). This might be explained by the fact that the migrant workers who had left the village probably included the healthiest of the men, thus creating an unexpected bias in the population surveyed.

\section{CLINICAL POLYARTHRITIS}

A history of polyarthralgia was frequently obtained, especially among the older respondents. However, this was seldom accompanied by any physical sign of polyarthritis. No one presented with a clinical picture immediately suggestive of rheumatoid arthritis; the seven individuals who were rated positive in the clinical assessment showed only the slightest features of inflammatory joint disease.

Both Greenwood (1969) and Kanyerezi and others (1970), on the basis of hospital studies, have commented on the mildness of the disease in the African. Whether this represents a different type of inflammatory polyarthritis, or whether it is due to modification of the universally recognizable rheumatoid disease, remains unresolved. It may be significant that only two of the individuals with clinical polyarthritis in the present survey had positive tests for rheumatoid serum factor.

\section{EROSIVE ARTHRITIS}

Radiological signs of erosive arthritis of the hands or feet occurred in $1.6 \%$ of the 801 subjects over 15 years, all of whom were $x$-rayed. In 222 respondents aged 35-64 years there were seven with at least grade 2 erosive arthritis, a prevalence of $3.2 \%$. This is similar to the prevalence in other parts of the world (Lawrence, Behrend, Bennett, Bremner, Burch, Gofton, O'Brien, and Robinson, 1966). However, the radiological changes in the African correlated poorly with either clinical or serological abnormalities.

\section{RHEUMATOID SERUM FACTOR}

The high prevalence of seropositivity with the LFT in African populations has been commented on by a number of investigators (Valkenburg, 1963; Lawrence, 1963; Muller, 1970). In the Tswana of Phokeng titres were not quite as high as those reported by Muller (1970) from two villages in Western Nigeria, but they were significantly higher than those of a standard population in the Netherlands. (Uniformity of interpretation of these results was assured by the fact that the Netherlands, Nigerian, and South African sera were tested in the same laboratory.) By contrast, low titres were recorded with the HEAT, $2.3 \%$ of all sera tested giving positive results as compared with $2.0 \%$ in the Dutch population (Muller, 1970).

The significance of these findings is uncertain, but the observations of Adler, Abramson, Goldberg, Elkan, and Ben Hador (1967) suggest that a high degree of seropositivity in Africans is largely an acquired characteristic.

It is well known that a variety of infections are associated with a positive LFT. These include leprosy (Cathcart, Williams, Ross, and Calkins, 1961 ; Abe, Chinone, and Hirako, 1967), kalaazar (Houba and Allison, 1966), trypanosomiasis (Klein and Mattern, 1965), malaria (Greenwood, 1968), and pulmonary tuberculosis (Singer, Plotz, Peralta, and Lyons, 1962), as well as a number of noninfective diseases associated with immunoglobulin abnormalities (Holley, Hammack, and Douglas, 1961 ; Bartfeld, 1969). Of these many disorders only pulmonary tuberculosis is known to have been common in Phokeng until 
recent times. The various parasitic infections are virtually unknown in this area. Multiple myeloma is also more common in the South African Negro than in the Caucasian population, but no specific data on this condition is available for Phokeng.

We are grateful to Chief Mokgatle and the Council of Phokeng and to the Department of Bantu Administration and Development for their consent for this investigation to be undertaken. We are indebted to the President of the Human Sciences Research Council, Pretoria, for his provision of computer facilities.

P.B. was in receipt of a Geigy Fellowship awarded by the Arthritis and Rheumatism Council of Great Britain. The project was supported jointly by the Orthopaedic Chair Trust Fund and the Carl and Emily Fuchs Foundation.

\section{References}

Abe, M., Chinone, S., ANd HiRako, T. (1967) Int. J. Leprosy, 35, 336 (Rheumatoid-factor-like substance and antistreptolysin $\mathrm{O}$ antibody in leprosy serum)

Adler, E., Abramson, J. H., Goldberg, R., Elkan, Z., and Ben Hador, S. (1967) Amer. J. Epid., 85, 378 (Rheumatoid arthritis in a Jerusalem population: 2. Epidemiology of rheumatoid factors)

ANDERSON, I. F. (1971) S. Afr. med. J., 45, 1032 (Rheumatoid arthritis in the Bantu)

BartFeld, H. (1969) Ann. N.Y. Acad. Sci., 168, 30 (Distribution of rheumatoid factor activity in nonrheumatoid states)

Bunim, J. J., Burch, T. A., ANd O’Brien, W. M. (1964) Bull. rheum. Dis., 15, 349 (Influence of genetic and environmental factors on the occurrence of rheumatoid arthritis and rheumatoid factor in American Indians)

CathCart, E. S., Williams, R. C., JR., Ross, H., and Calkins, E. (1961) Amer. J. Med., 31, 758 (The relationship of the latex fixation test to the clinical and serological manifestations of leprosy)

Cobb, S., Warren, J. E., Merchant, W. R., and Thompson, D. J. (1957) J. chron. Dis., 5, 636 (An estimate of the prevalence of rheumatoid arthritis)

DE GraAfF, R., LAine, V., AND LAWRenCE, J. S. (1963) 'Comparison of surveys in various Northern European Communities' in 'The Epidemiology of Chronic Rheumatism', ed. J. H. Kellgren, M. R. Jeffrey, and J. Ball, p. 228. Blackwell, Oxford

Gelfand, M. (1969) Cent. Afr. J. Med., 15, 131 ('Medical' arthritis in African practice)

GreENWOOD, B. M. (1968) Lancet, 2, 380 (Autoimmune disease and parasitic infections in Nigerians) (1969) Ann. rheum. Dis., 28, 488 (Polyarthritis in Western Nigeria: I. Rheumatoid arthritis)

Hall, L. (1966) E. Afr. med. J., 43, 161 (Polyarthritis in Kenya)

Holley, H. L., Hammack, W. J., and Douglas, C. (1961) Amer. J. med. Sci., 242, 331 (The application of the sensitized sheep cell test to sera of patients with nonrheumatic diseases and false positive serological reactions for rheumatoid arthritis)

Houba, V., AND Allison, A. C. (1966) Lancet, 1, 848 (M-antiglobulins (rheumatoid factor-like globulins) and other gamma-globulins in relation to tropical parasitic infections)

KANYEREZI, B. R. (1969) E. Afr. med. J., 46, 71 (Rheumatoid arthritis in Uganda)

- Baddeley, H., AND Kisumba, D. (1970) Ann. rheum. Dis., 29, 617 (Rheumatoid arthritis in Ugandan Africans)

Kellgren, J. H., JefFrey, M. R., ANd Ball, J. (1963a) In 'The Epidemiology of Chronic Rheumatism', Vol. 1. Blackwell, Oxford

(1963b) In 'The Epidemiology of Chronic Rheumatism. Vol. 2. Atlas of Standard Radiographs of Arthritis'. Blackwell, Oxford

Klein, F., ANd Mattern, P. (1965) Ann. rheum. Dis., 24, 458. (Rheumatoid factors in primary and reactive macroglobulinaemia)

LAINE, V. A. I. (1962) Acta rheum., scand., 8, 81 (Rheumatic complaints in an urban population in Finland)

LAWRENCE, J. S. (1963) Arthr. and Rheum., 6, 166 (Epidemiology of rheumatoid arthritis) (1969) In 'Textbook of the Rheumatic Diseases,' ed. W. S. C. Copeman, 4th ed., p. 163. Livingstone, Edinburgh and London

- Behrend, T., Bennett, P. H., Bremner, J. M., Burch, T. A., Gofton, J., O’Brien, W., And Robinson, H. (1966) Ann. rheum. Dis., 25, 425 (Geographical studies on rheumatoid arthritis)

, Bremner, J. M., BALl, J., AND BurCh, T. A. (1966) Ibid., 25, 59 (Rheumatoid arthritis in a subtropical population)

Muller, A. S. (1970) Population Studies on the Prevalence of Rheumatic Diseases in Liberia and Nigeria. MD Thesis, University of Leiden.

Ropes, M. W., Bennett, G. A., Cobb, S., Jacox, R., And Jessar, R. A. (1959) Ann. rheum. Dis., 18, 49 (Diagnostic criteria for rheumatoid arthritis: 1958 revision)

Singer, J. M., Plotz, C. M., Peralta, F. M., AND Lyons, H. C. (1962) Ann. intern. Med., 56, 545 (The presence of antigamma globulin factors in sera of patients with active pulmonary tuberculosis)

VAlKENBURG, H. A. (1963) 'Rheumatoid factor in populations', in 'The Epidemiology of Chronic Rheumatism', ed. J. H. Kellgren, M. R. Jeffrey, and J. Ball, Vol. 1, p. 74. Blackwell, Oxford 